\title{
PERCEIVED QUALITY OF TRANSITIONAL CARE BETWEEN PUBLIC HOSPITAL AND PUBLIC HEALTH CARE CLINIC IN NEGERI SEMBILAN, MALAYSIA: A PILOT STUDY
}

\author{
Farhana Md Yusof ${ }^{1}$ and Chai-Eng Tan ${ }^{2}$ \\ ${ }^{1}$ Ministry of Health Malaysia, c/o Klinik Kesihatan Sungai Tekam Utara, 27060 Jerantut, Malaysia \\ ${ }^{2}$ Department of Family Medicine, Faculty of Medicine, Universiti Kebangsaan Malaysia,Jalan Yaakob Latif, Cheras \\ 56000, Kuala Lumpur, Malaysia
}

Corresponding author: Farhana Md Yusof

Email: farhanamdyusof@gmail.com

\begin{abstract}
Quality of transitional care affects healthcare spending and service use. Poor transitional care is associated with adverse effects such as medication error and risk of unnecessary readmission. The objective of this study is to evaluate patients' perception of quality of transitional care from a public tertiary hospital to a public health clinic in Negeri Sembilan. A cross-sectional study was conducted involving 307 respondents from the public health clinic following discharge from the hospital from July to September 2018. Patient's perception of quality of transitional care was measured using the Care Transitional Measure (CTM $\left.15^{\circledR}\right)$ questionnaire. The response rate for this study was $90.6 \%$. The mean $C T M-15^{\circledR}$ score was $73.1( \pm 13.03)$ out of a scale of 1 to 100 . The mean scores for the various domains were: Critical understanding was $73.3( \pm 14.33)$, Preferences important was $71.9( \pm 14.99)$, Management preparation was 74.0 $( \pm 14.53)$, and Care plan $73.3( \pm 14.75)$. Multiple linear regression showed that age was a significant independent predictor for the CTM-15 ${ }^{\circledR}$ scores where elderly patients had poorer scores than young adults (adjusted $R^{2}=0.104$, $p<0.001)$. In conclusion, the perceived quality of transitional care between the public general hospital and health clinic was good but decreased with patient's age. This could be due to complexity of the patient's problems upon discharge.
\end{abstract}

Keyword: Transitional care, quality of health care, primary health care, patient discharge

\section{INTRODUCTION}

American Geriatrics Society defines transitional care as "a set of actions designed to ensure the coordination and continuity of health care as a patient transfers between different level of care" 1 . Patient care is usually transferred from hospital to primary care after being discharged from the ward. Transitional care is not limited to the geriatric population, but is applicable to any discipline, to ensure a smooth transition between levels of care. In Malaysia, patients that require transitional care include those with complex medical needs (e.g. stroke with neurological deficits and multiple comorbidities), patients with chronic diseases that can be followed up at the primary care setting (e.g. patients with diabetes where significant changes to medications as well as newly detected complications), post-natal patients (e.g. ensuring maternal and infant safety during the post-partum period), and patients who have recently undergone surgical or invasive procedures (e.g. post-laparotomy patients who require wound dressing).

There are risks to patient safety during this transition. Medication discrepancy and increasing number of hospital readmissions was resulted from poor quality of transitional care ${ }^{2,3}$. In the United States, one in five patients experienced adverse event during transition from hospital to home largely due to adverse drug events, of which
$6 \%$ were preventable 4 . In fact, error in transitional care is recognized as a preventable morbidity by World Health Organization ${ }^{5}$. It is therefore essential to assess our quality of transitional care to identify shortfalls and intervene to avoid such undesirable outcomes.

Poorly coordinated transfer of care can occur due to communication deficiencies between hospital and primary care team, as well as between the healthcare provider and patient $\mathrm{t}^{6-8}$, psychosocial factors of the patients ${ }^{9}$ and complexity of the disease ${ }^{10}$ are also relevant contributing factors. It is important for clinicians to realise this while planning for transfer of care.

Lack of communication between hospital and primary care team was highlighted by the Quality of Primary Care Services (QUALICO-PC) survey in Malaysia. Only $40 \%$ of the primary care doctors received feedback from the hospital following their referral and received discharge summaries after their patients were discharged ${ }^{11}$. The lack of communication and partnership with primary care physician was associated with patient safety issues, especially failure in completing management after discharge ${ }^{12,13}$.

For the past two decades, transitional care research has primarily focused on the experiences of elderly with chronic illnesses and those with complex medical conditions ${ }^{1,14}$. Since quality of 
transitional care has been proven to contribute to healthcare spending and service use due to unnecessary hospital readmission ${ }^{15}$. Lately, more attention has been focused on the evaluation of intervention models like post discharge telephone support and home visiting program on their efficacy to reduce unnecessary readmission and patient safety ${ }^{16,17}$. To date, quality of transitional care in Malaysia have yet to be assessed. It is essential to assess quality of transitional care here in Malaysia as a benchmark against other countries and to identify gaps in the provision of care.

The aim of this study is to evaluate patients' perception of quality of transitional care from a public general hospital to a public health clinic. This study also aimed to look for other factors that may influence quality of transitional care particularly sociodemographic and admission profile factor.

\section{METHODOLOGY}

\section{Study design and participant}

This was a cross sectional study conducted among patients who were discharged from a public hospital and referred to a large public health clinic for continuation of care, in Negeri Sembilan, Malaysia. The patients who were eligible to be included into the study were at least 18 years of age 1)had been admitted to the hospital for at least one night within the last six months 2)had their care transferred to Public Health Clinic upon discharge and 3) able to understand and read Malay or English. Patients who lacked capacity to provide written consent and admitted for psychiatric illness were excluded.

\section{Sample size}

Sample size was determined to estimate a population mean, with a confidence interval of $95 \%$ and precision of 1 . A minimum of 271 respondents was required. This was increased to 339 accommodate for a possibility of $20 \%$ nonresponse rate.

\section{Study procedure}

We used convenience sampling due to difficulty in identifying potential respondents in the clinic. Data collection was conducted from July to September 2018. Potential respondents were recruited from the registration counter outpatient department, maternal and child health clinic and procedure rooms. Most of the case referred to primary care in this study was chronic disease and postpartum. Patients who fulfilled the inclusion and exclusion criteria were invited to participate. They received a written patient information sheet after a brief verbal explanation, and their written consent was obtained. Participants who provided written consent would then complete a questionnaire with minimal researcher assistance. Their participation did not affect their subsequent consultation and the researcher was not involved in their clinical management, to avoid potential bias in their responses.

\section{Study Instrument}

A standardized data collection form was used to collect basic demographic data (i.e. patient age, gender, ethnicity, educational level and household income) as well as admission profile (ward discipline, length of admission and types of admission).

Care Transitional Measure (CTM 15) ${ }^{\circledR}$ was used to assess patient's perception regarding quality of discharge transition. CTM $15^{\circledR}$ consists of 15 items representing four domains: 1) critical understanding, 2) preferences important 3) management preparation and 4) care $\operatorname{plan}^{18}$. The CTM $15^{\oplus}$ had good internal consistency reliability $(\text { Cronbach a: } 0.93)^{18}$. The CTM $15^{\circledR}$ items were rated on a four-point Likert scale ranging from 1 = 'strongly disagree' to 4 = 'strongly agree'. If a fifth response being 'don't know/don't remember/not applicable' was selected, the item was excluded from the calculation of the final score. The mean scores of the items were converted into a linear scale ranging between 0 and 100 , to obtain the final CTM $15 \otimes$ score as per previous study. This final score reflects the overall quality of the care transition, with higher scores indicating better transition quality.

CTM $15^{\circledR}$ was initially translated into Malay language in a previous study in Singapore 19 however the Malay language version was not validated. For this study, face validity was tested among 5 subjects for both Malay and English versions of CTM $15^{\circledR}$. Minor amendments were made to improve clarity and comprehensibility based on feedback from face validation.

A pilot study was conducted involving 25 subjects using the refined Malay version of CTM $15^{\circledR}$. The internal consistency of the CTM $15^{\circledR}$ from our pilot study was excellent (Cronbach a: 0.91). The aim of this pilot study was to test the feasibility of the study and to determine the internal consistency of the amended Malay version for this study. Construct validity was not tested.

\section{Statistical analysis}

Data were analysed using SPSS version 25. Incomplete questionnaires with missing data in sociodemographic or admission profile section were excluded from the analysis.

Descriptive data were generated for all variables including frequencies, percentages, means and standard deviations or median and interquartile ranges. Non-parametric analyses such as MannWhitney rank-sum test and Kruskal-Wallis test were used for inferential analysis due to the skewed data distribution. Dunn's pairwise tests were carried out for each significant variable and adjusted using Bonferroni correction. Statistical significance was set at $p<0.05$. 
We categorized length of hospital stay based on $25^{\text {th }}, 50^{\text {th }}, 75^{\text {th }}$ quartiles whereas age was categorized based on WHO classifications.

Multiple linear regression was used to assess ability of sociodemographic data and admission profile to predict quality of transitional care.

\section{Ethical statement}

This study received ethical clearance from the University Medical Research and Ethics Committee (approval code: FF-2017-485) as well as the Ministry of Health Medical Research and Ethics Committee (approval code: NMRR-17-209537520). Approval from the state department of health was also obtained to conduct this study.

\section{RESULTS}

The response rate for this study was $90.6 \%$. Responses from only 307 respondents were analysed after excluding those with missing data. Sociodemographic data and admission profile are summarized in table 1 . The current study population was predominantly female with up to secondary school education and from lower income groups. There was a fair mix of ethnic groups and types of admissions. Most of the study respondents were antenatal and post-natal patients discharged from the obstetrics and gynaecology wards. From our study, the mean CTM $15^{\circledR}$ score was $73.1( \pm 13.03)$ out of a scale of 1 to 100 . The mean scores for the various domains were: critical understanding was $73.3( \pm 14.33)$, preferences important was $71.9 \quad( \pm 14.99)$, management preparation was $74.0( \pm 14.53)$, and care plan was $73.3( \pm 14.75)$.

Table 1: Sociodemographic data and admission profile of the respondent

\begin{tabular}{|c|c|c|}
\hline Variable $(n=307)$ & $\mathrm{n}$ & $\%$ \\
\hline \multicolumn{3}{|l|}{ Age } \\
\hline (18-24 years) & 34 & 11.1 \\
\hline (25-44 years) & 176 & 57.3 \\
\hline Middle age ( $45-64$ years) & 66 & 21.5 \\
\hline Elderly $\quad$ (>65years) & 31 & 10.1 \\
\hline \multicolumn{3}{|l|}{ Gender } \\
\hline Male & 82 & 26.7 \\
\hline Female & 225 & 73.3 \\
\hline \multicolumn{3}{|l|}{ Ethnicity } \\
\hline Malay & 122 & 39.7 \\
\hline Chinese & 80 & 26.1 \\
\hline Indian & 98 & 31.9 \\
\hline Others & 7 & 2.3 \\
\hline \multicolumn{3}{|l|}{ Educational Level } \\
\hline No formal education & 18 & 5.9 \\
\hline Primary school & 46 & 15.0 \\
\hline Secondary School & 145 & 47.2 \\
\hline College/University & 98 & 31.9 \\
\hline \multicolumn{3}{|l|}{ Household Income } \\
\hline Low & 222 & 72.3 \\
\hline Medium & 69 & 22.5 \\
\hline High & 16 & 5.2 \\
\hline \multicolumn{3}{|l|}{ Ward discipline } \\
\hline Medical & 63 & 20.5 \\
\hline Surgical & 84 & 27.4 \\
\hline Obstetrics and Gynaecology & 158 & 51.5 \\
\hline Others( rehab) & 1 & 0.3 \\
\hline \multicolumn{3}{|l|}{ Types of admission } \\
\hline Elective & 113 & 36.8 \\
\hline Emergency & 194 & 63.2 \\
\hline \multicolumn{3}{|l|}{ Length of stays days } \\
\hline Median (IQR) & $3(4)$ & \\
\hline Range & 2-52 days & \\
\hline
\end{tabular}


Table 2: Bivariate analysis between sociodemographic data and admission profile and median CTM $15 \circledast$

\begin{tabular}{|c|c|c|c|c|c|}
\hline Variable & Mean rank & Median & $\mathrm{U}$ & Z & $\mathrm{P}$ value \\
\hline $\begin{array}{l}{ }^{\mathrm{a}} \text { Gender } \\
\text { Male } \\
\text { Female }\end{array}$ & $\begin{array}{l}126.1 \\
164.2\end{array}$ & $\begin{array}{l}66.67 \\
66.67\end{array}$ & 6940 & -3.466 & $0.001^{* *}$ \\
\hline $\begin{array}{ll}{ }^{\mathrm{b}} \text { Age } & \\
\text { Youth } & (18-24 \text { years }) \\
\text { Adult } & (25-44 \text { years) } \\
\text { Middle age } & (45-64 \text { years }) \\
\text { Elderly } & (>65 \text { years })\end{array}$ & $\begin{array}{l}173.3 \\
166.6 \\
164.7 \\
105.0\end{array}$ & $\begin{array}{l}69.04 \\
66.67 \\
66.67 \\
66.67\end{array}$ & & $\begin{array}{r}X^{2} \\
18.603\end{array}$ & $\begin{array}{l}\mathrm{P} \text { value } \\
<0.001^{* *}\end{array}$ \\
\hline $\begin{array}{l}\text { b Ethnicity } \\
\text { Malay } \\
\text { Chinese } \\
\text { Indian and Others }\end{array}$ & $\begin{array}{l}169.0 \\
152.5 \\
137.1\end{array}$ & $\begin{array}{l}67.78 \\
66.67 \\
66.67\end{array}$ & & 7.659 & $0.022^{* *}$ \\
\hline $\begin{array}{l}\text { b Educational Level } \\
\text { No Formal Education } \\
\text { Primary school } \\
\text { Secondary School } \\
\text { College/University }\end{array}$ & $\begin{array}{l}118.3 \\
126.2 \\
151.9 \\
176.8\end{array}$ & $\begin{array}{l}66.67 \\
66.67 \\
66.67 \\
72.22\end{array}$ & & 15.217 & $0.002^{* *}$ \\
\hline $\begin{array}{l}\text { bousehold Income } \\
\text { Low } \\
\text { Medium } \\
\text { High }\end{array}$ & $\begin{array}{l}144.4 \\
182.7 \\
164.1\end{array}$ & $\begin{array}{l}66.67 \\
73.33 \\
71.11\end{array}$ & & 10.944 & $0.004^{* *}$ \\
\hline 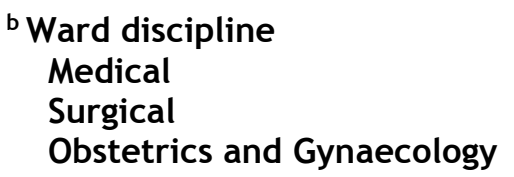 & $\begin{array}{l}135.3 \\
129.3 \\
174.9\end{array}$ & $\begin{array}{l}66.67 \\
66.67 \\
66.67\end{array}$ & & 19.742 & $<0.001^{* *}$ \\
\hline $\begin{array}{l}\text { b Length of stay } \\
0-2 \text { days } \\
3-5 \text { days } \\
>6 \text { days }\end{array}$ & $\begin{array}{l}158.6 \\
161.9 \\
135.8\end{array}$ & $\begin{array}{l}66.67 \\
66.67 \\
66.67\end{array}$ & & 5.124 & 0.077 \\
\hline $\begin{array}{l}{ }^{a} \text { Types of admission } \\
\text { Elective } \\
\text { Emergency }\end{array}$ & $\begin{array}{l}165.9 \\
147.1\end{array}$ & $\begin{array}{l}66.67 \\
66.67\end{array}$ & $\begin{array}{r}U \\
9617\end{array}$ & $\begin{array}{r}Z \\
-1.870\end{array}$ & $\begin{array}{r}P \text { value } \\
0.061\end{array}$ \\
\hline
\end{tabular}

${ }^{a}$ Mann Whitney $U$ test ${ }^{b}$ Kruskal Wallis $H$ test ${ }^{* *}$ significant $P<0.05$, regression coefficient

It can be seen from the data in Table 2 that there were significant differences in the mean ranks for the CTM 15® score between various sociodemographic factors and ward disciplines. However, there were no significant differences between length of admission and types of admission.

Female patients had higher mean rank for the CTM $15 \circledR$ scores compared to males. This could be due to the high preponderance of patients discharged from the obstetric wards for postnatal care. This also possibly explained the significantly higher mean rank scores for those discharged from the obstetrics and gynaecology wards (174.9) compared to surgical wards (129.3) and medical wards (135.3). Mean rank for CTM $15 \AA$ scores were significantly lower among elderly (105.0) compared to youth age group patients (173.3 There was also a stark difference between mean rank scores for Indian patients (137.1) compared to Malay patients (169.0). Mean rank for CTM 15® were significantly higher among respondent who received tertiary education (176.8) compared to no formal education (118.3) and primary school level (126.2). Low income patients had a lower mean rank score for CTM 15® (144.4) compared to middle income patients. 
Multiple linear regression model statistically significantly predicted mean CTM $15 \otimes$ score, $[F(16,290) p<.0001$, adj. $R 2=0.145]$. Age was found as significant factors to determine mean CTM $15 \AA$ as shown in Table 3. Elderly age was independently associated with lower quality of transitional care. However, age factor only explained about $14.5 \%$ of the variation in mean CTM 15® score. Other variables were tested (e.g. gender, income, educational level, ward discipline, types of admission and length of admission) but none was significant.

Table 3: Multiple regression analysis predicting mean Care Transitional Measure-15®

\begin{tabular}{|c|c|c|c|c|c|}
\hline Variable & & B & $\begin{array}{l}\text { Standard } \\
\text { error }\end{array}$ & B & $\mathbf{P}$ \\
\hline Constant & & 75.24 & & & \\
\hline \multirow[t]{2}{*}{ Gender } & Male & \multicolumn{4}{|c|}{ Reference } \\
\hline & Female & 1.987 & 2.180 & 0.068 & 0.363 \\
\hline \multirow[t]{4}{*}{ Age } & youth & \multicolumn{4}{|c|}{ Reference } \\
\hline & Adult & -4.821 & 2.565 & 0.183 & 0.061 \\
\hline & Middle age & -5.211 & 2.841 & 0.166 & 0.068 \\
\hline & Elderly & -7.146 & 3.402 & 0.163 & $0.037^{*}$ \\
\hline \multirow[t]{3}{*}{ Income } & Low & \multicolumn{4}{|c|}{ Reference } \\
\hline & Medium & 3.080 & 2.045 & 0.099 & 0.133 \\
\hline & High & 3.388 & 3.415 & 0.058 & 0.322 \\
\hline \multirow[t]{2}{*}{ Ethnicity } & Malay & Reference & & & \\
\hline & Chinese & 0.826 & 1.888 & 0.028 & 0.662 \\
\hline \multirow{4}{*}{$\begin{array}{l}\text { Educational } \\
\text { level }\end{array}$} & $\begin{array}{l}\text { Indian and others } \\
\text { No formal education }\end{array}$ & \multicolumn{4}{|c|}{ Reference } \\
\hline & Primary school & 0.979 & 3.548 & 0.027 & 0.276 \\
\hline & Secondary school & 0.288 & 3.252 & 0.011 & 0.088 \\
\hline & College/ University & 3.511 & 3.579 & 0.126 & 0.981 \\
\hline \multirow{3}{*}{$\begin{array}{l}\text { Ward } \\
\text { discipline }\end{array}$} & Obstetrics \& Gynaecology & \multicolumn{4}{|c|}{ Reference } \\
\hline & Surgical & -3.624 & 2.980 & 0.124 & 0.225 \\
\hline & Medical & -3.033 & 2.806 & 0.095 & 0.281 \\
\hline \multirow{2}{*}{$\begin{array}{l}\text { Type of } \\
\text { admission }\end{array}$} & Elective & \multicolumn{4}{|c|}{ Reference } \\
\hline & Emergency & -2.108 & 1.550 & -0.078 & 0.175 \\
\hline \multirow{3}{*}{$\begin{array}{l}\text { Duration of } \\
\text { admission }\end{array}$} & $0-2$ days & \multicolumn{4}{|c|}{ Reference } \\
\hline & 3-5 days & 3.084 & 1.742 & 0.118 & 0.078 \\
\hline & $>6$ days & 2.139 & 2.158 & 0.073 & 0.322 \\
\hline
\end{tabular}

${ }^{*}$ significant at $P<0.05 ; B=$ unstandardized

\section{DISCUSSION}

Prior studies have highlighted the importance of good transitional care. In this study, we evaluated quality of transitional care by using CTM $15^{\circledR}$. We found that our mean CTM $15^{\circledast}$ score was $73.1( \pm 13.03)$. This result was comparable with earlier studies in developed countries using the same study instrument, such as in Singapore which reported a mean $\mathrm{CTM} 15^{\circledR}$ score of $66.0( \pm 14.7)^{19}$, in Japan which reported a mean score of
$66.32( \pm 14.0)^{20}$, and in the United States with a mean score of $73.9( \pm 16.17)^{21}$. This could reflect differences in expectations and healthcare systems. In Malaysia, public hospitals provide services for a very minimal fee compared to private hospitals. On the other hand, Singapore healthcare subsidies in public hospitals are very much targeted towards specific income groups and healthcare insurance plays an important role in financing ${ }^{22}$. Similarly, healthcare in Japan and United States are largely funded by healthcare 
insurance. This could affect patients' expectations towards the services provided ${ }^{23}$ and subsequently their perceptions of quality of transitional care.

Satisfaction level of transitional care was poorer among men, elderly age group, Indian ethnicity, low household income and low educational level. This result is consistent with previous studies which found similar poorer quality of transitional care among older age, ${ }^{21}$ low household income and low educational level ${ }^{21,24}$. Further research is required to further examine the reason for this disparity.

Increasing age is independently associated with poorer quality of transitional care. Our findings show that elderly patients had lower satisfaction for transitional care, which could be explained by their more complex transition care needs ${ }^{25}$. Furthermore, there were increasing evidence that elderly patients were more likely to have medication errors during discharge ${ }^{2,26}$ due to multiple comorbidities or chronic diseases. Having complex medical needs required more measures to ensure a smoother transition, which could result in gaps if not carefully executed. This could explain their views on quality of transitional care in this study.

Health literacy also plays an important role in transitional care. Patients with lower health literacy required more assistance during the transition compared to those with adequate health literacy ${ }^{27}$. Furthermore, a systemic review found low health literacy is associated with increased frequency of hospitalization and emergency care use. They also found elderly patients are most likely to have poor overall health status and mortality rate $^{28}$. This may explain why younger patients have better quality of transitional care in comparison to elderly patients. Besides, level of health literacy also explained our findings that poor perception of quality of transitional care among $\operatorname{men}^{29}$, low household income and lower educational level ${ }^{30,31}$. This remains to be confirmed by further research on local health literacy.

Socioeconomic status affects individual's perception on quality of health care ${ }^{32}$. Our finding is consistent with reports of low socioeconomic status having poor quality of transitional care can $^{33}$ but patients from higher income groups also perceived lower quality of transitional care compared to the middle income group. This could stem from different expectations towards healthcare services. It is possible that those with higher socioeconomic status expected better quality of services as suggested with previous study $^{34}$.

We found significantly higher perceived quality of transitional care among patients who were admitted into obstetrics and gynaecology ward, in contrast with medical and surgical wards. In Malaysia, both antenatal and postnatal discharges are more structured and less complicated compared to other disciplines. There is an existing system for transfer of care to the community maternal and child health services. After delivery, the patients are given a standard set of advice and medications, as well as an instruction to register with the public health clinic. The notification of the public health clinic would initiate a system for postnatal services including postnatal home visits by community nurses and scheduled postnatal clinic appointments. The services also provide checking the newborn for possible problems, neonatal jaundice and breastfeeding support ${ }^{35}$. In contrast, discharges from other disciplines are less structured which could be due to more complex conditions such as post-surgical procedures or acute medical problems. For such cases, there is no standardised discharge protocol in place due to the diverse nature of the patients' problems. This could possibly lead to certain gaps in transitional care to the primary care side.

Malaysia has a multi-ethnic population with diverse cultures. Malay respondents in this study reported better transitional care compared to Indian respondents. This could be related to the language barrier faced by respondents who could not converse well in Malay or English. Although these two languages are taught in formal education, actual written and oral competencies vary among the local population. Language barrier associated with poor understanding about prescribed medication and types of follow up ${ }^{36}$ affect the quality of transitional care. These may lead to frustration with the instructions or explanations given during discharge.

Length of admission and type of admission was not associated with the perceived quality of transitional care. Although these findings contradicted with a study in Egypt, but this inconsistency may be due to different selection of samples ${ }^{37}$. In their study, selection of respondents limited into medical inpatient while this study involves all inpatient departments in tertiary hospital.

\section{Strengths and limitations}

This study was a pilot study on the quality of transitional care in a local public hospital to the health clinic. The original English CTM $15 \AA$ was a validated questionnaire, which was used to assess patient's perceived quality of transitional care. Using the CTM 15 as a tool allows for some degree of comparison between countries such as Singapore and the United States.

However, there were certain limitations to this study. The Malay version of CTM $15 \AA$ only underwent linguistic and face validation, and 
internal consistency testing. It did not undergo the full process of construct validity. However, the good internal consistency reliability may support the uni-factorial structure of the tool. The CTM $15 \otimes$ measured patient's perceptions regarding the quality of transitional care received. It does not encompass other measures of quality of transitional care such as appropriateness of the management plan, quality of communication and clinical outcomes such as unplanned hospital readmission.

The current study also lacks generalisability due to convenience sampling. There is possibility of sampling bias and response bias. Furthermore, the eligibility criteria included those respondents who were admitted within the last six months, undeniably increasing the possibility of recall bias. Moreover, this study only recruited those presented to single public health clinic. Those who were discharged to other clinic or home or those who defaulted follow up were probably have been missed by us to be included in this study. Also, we did not include diagnosis of admission as one of the variables which may influence quality of transitional care.

\section{Recommendation}

Firstly, the construct validity of the Malay version of the CTM $15 \otimes$ should be tested to strengthen the validity of the tool. The study may be improved with a more systematic data collection from various disciplines and to include patients who may be discharged home or to other clinics. It should also be followed by an audit into the discharge process and identify areas for improvement. Obtaining qualitative feedback from the patients may provide additional information on the areas of need.

Since the current study suggests lower perceived quality of transitional care among older patients, clinicians should consider planning a more structured and comprehensive discharge plan for this group. A checklist to ensure that all components of discharge planning are not left out may be helpful to improve the perceived quality of transitional care for this group. From the primary care side, we could educate our patients on important information that they must obtain and understand prior to discharge. Improving communication and information-sharing between the hospital and primary care is essential to allow for smoother transition of care.

\section{CONCLUSIONS}

Patients' perceived quality of transitional care from this public hospital to the primary care clinic was comparable with other studies conducted in other developed countries. Lower perceived quality of transition care was associated with elderly age group, men, low household income, low educational level, Indian ethnicity as well as medical or surgical ward admission. Age, however, was an independent predictor for the perceived quality of transitional care.

\section{Acknowledgment}

The authors would like to thank the Director General of Health Malaysia for the permission to publish this paper.

\section{Funding}

This study is not funded by any organisation.

\section{Conflict of interest}

This study has no conflict of interest

\section{REFERENCES}

1. Coleman EA, Boult C. Improving the quality of transitional care for persons with complex care needs. J Am Geriatr Soc. 2003;51(4):556-557.

2. Scales DC, Fischer HD, Li $P$, et al. Unintentional Continuation of Medications Intended for Acute Illness After Hospital Discharge: A Population-Based Cohort Study. J Gen Intern Med. 2016;31(2):196202.

3. Goldstein JN, Hicks LRS, Kolm P, Weintraub WS, Elliott DJ. Is the Care Transitions Measure Associated with Readmission Risk? Analysis from a Single Academic Center. J Gen Intern Med. 2016;31(7):732-738.

4. Forster AJ, Murff HJ, Peterson JF. The Incidence and Severity of Adverse Events Affecting Patients after Discharge from the Hospital. Ann Intern Med. 2003;138(3):161.

5. WHO. The High 5s Project: Interim Report. 2014:123.

http://www.who.int/patientsafety/impl ementation/solutions/high5s/en/.

6. Barach P, Gademan P, Dudzik-urbaniak E, Flink M. Organizational Culture An Important Context for Addressing and Improving Hospital to Community Patient Discharge. Med Care. 2013 Jan;51(1):90-8

7. Hesselink G, Schoonhoven L, Plas M, Wollersheim $H$, Vernooij-Dassen $M$. Quality and safety of hospital discharge: A study on experiences and perceptions of patients, relatives and care providers. Int J Qual Heal Care. 2013;25(1):66-74.

8. Kattel S, Manning DM, Erwin PJ, Wood H, Kashiwagi DT, Murad MH. Information Transfer at Hospital Discharge: A Systematic Review. J Patient Saf. 2016 
Jan 7. [Epub ahead of print]

9. Corona-lobos L, Harduin M, Boivin C. Psychosocial Factors Associated with Hospital-to-Home Transitions of Older People : A Review. J Nurs Care ,2018;7(4).

10. Desai AD, Durkin LK, Jacob-Files EA, Mangione-Smith R. Caregiver Perceptions of Hospital to Home Transitions According to Medical Complexity: A Qualitative Study. Acad Pediatr. 2016;16(2):136-144.

11. Sivasampu, Sheamini \& Noh, Kamaliah \& May Chien, Chin. (2015). Quality and Costs of Primary Care (QUALICOPC)- Malaysia Phase 1 Report 2015.

12. Roy CL, Poon EG, Karson AS, et al. Patient safety concerns arising from test results that return after hospital discharge. Ann Intern Med. 2005;143(2):121-128.

13. Moore C, McGinn T HE. Tying up loose ends: discharging patients with unresolved medical issues. Arch Intern Med. 2007 Jun 25;167(12):1305-11.

14. Allen $J$, Hutchinson $A M$, Brown $R$, Livingston PM. Quality care outcomes following transitional care interventions for older people from hospital to home: a systematic review. BMC Heal Serv Res. 2014;14:346.

15. Jencks SF, Williams M V., Coleman EA. Rehospitalizations among patients in the Medicare Fee-for-Service Program. N Engl J Med. 2009;360(14):1418-1428.

16. Wang $\mathrm{Y}$, Yang $\mathrm{F}$, Shi $\mathrm{H}$, Yang $\mathrm{C}$, Hu H. What type of transitional care effectively reduced mortality and improved ADL of stroke patients? A meta-analysis. Int $J$ Environ Res Public Health. 2017;14(5):117.

17. Laugaland K, Aase K, Barach $\mathrm{P}$. Interventions to improve patient safety in transitional care - A review of the evidence. Work. 2012;41(suppl.1):29152924.

18. Coleman EA, Mahoney E, Parry C. Assessing the quality of preparation for posthospital care from the patient's perspective: the care transitions measure. Med Care. 2005;43(3):246-255.

19. Bakshi AB, Wee SL, Tay C, et al. Validation of the care transition measure in multiethnic South-East Asia in Singapore. BMC Heal Serv Res. 2012;12:256.
20. Yoshimura M, Sato M, Sumi N. Validity and reliability of the Japanese version of the Care Transitions Measure. Int J Health Plann Manage. 2018 Apr;33(2):380-390

21. Anatchkova MD, Barysauskas CM, Kinney $\mathrm{RL}$, et al. Psychometric evaluation of the Care Transition Measure in TRACE-CORE: do we need a better measure? J Am Hear Assoc. 2014;3(3):e001053.

22. Lim J. Sustainable Health Care Financing: The Singapore Experience. Glob Policy. 2017;8(2):103-109.

23. Shan $L$, Li $Y$, Ding $D$, et al. Patient satisfaction with hospital inpatient care: Effects of trust, medical insurance and perceived quality of care. PLoS One. 2016;11(10):1-18.

24. Arbaje Al, Wolff JL, Yu Q, Powe NR, Anderson GF, Boult C. Postdischarge environmental and socioeconomic factors and the likelihood of early hospital readmission among community-dwelling Medicare beneficiaries. Gerontologist. 2008;48(4):495-504.

25. Storm M, Siemsen IMD, Laugaland $K$, Dyrstad DN, Aase K. Quality in transitional care of the elderly: Key challenges and relevant improvement measures. Int $J$ Integr Care. 2014;14(May):e013.

26. Mesteig M, Helbostad JL, Sletvold $O$, Røsstad T, Saltvedt I. Unwanted incidents during transition of geriatric patients from hospital to home: A prospective observational study. BMC Health Serv Res. 2010;10:1-9.

27. Boyle J, Speroff T, Worley K, et al. Low Health Literacy is Associated with Increased Transitional Care Needs in Hospitalized Patients. J Hosp Med. 2017;12(11):918-924.

28. Berkman ND, Donahue K, Berkman ND, et al. Low health literacy and health outcomes: an updated systematic review. Ann Intern Med. 2011 Jul 19;155(2):97107

29. Lee HY, Lee J, Kim NK. Gender Differences in Health Literacy Among Korean Adults: Do Women Have a Higher Level of Health Literacy Than Men? Am J Mens Health. 2015;9(5):370-379.

30. Sheikh H, Brezar A, Dzwonek A, Yau L, Calder LA. Patient understanding of discharge instructions in the emergency department: do different patients need 
different approaches? Int J Emerg Med. 2018;11(1).

31. Van Der Heide I, Wang J, Droomers M, Spreeuwenberg $\mathrm{P}$, Rademakers J, Uiters $\mathrm{E}$. The relationship between health, education, and health literacy: Results from the dutch adult literacy and life skills survey. J Health Commun. 2013;18(suppl. 1):172-184.

32. Kondo N, Sembajwe G, Kawachi I, Van Dam RM, Subramanian S V., Yamagata Z. Income inequality, mortality, and self rated health: Meta-analysis of multilevel studies. BMJ. 2009;339(7731):1178-1181.

33. Morales LS, Dial TH, Pincus HA, Haviland MG. Race/Ethnicity, Socioeconomic Status, and Satisfaction With Health Care. Am J Med Qual. 2005;20(4):195-203.
34. Pickard KE, Ingersoll BR. Quality versus quantity: The role of socioeconomic status on parent-reported service knowledge, service use, unmet service needs, and barriers to service use. Autism. 2016;20(1):106-115.

35. Division of Family Health Development Ministry of Health Malaysia. Perinatal Care Manual. third edition. 2013:136-162.

36. Karliner LS, Auerbach A, Nápoles A, Schillinger D, Nickleach D, J P-SE. Language barriers and understanding of hospital discharge instructions. Med Care. 2012;50(4):283-289.

37. Mosallam RA, Metwally S. Patients' views on the quality of transitional care at a health insurance hospital in Alexandria, Egypt. J Egypt Public Health Assoc. 2014;89(2):74-80. 